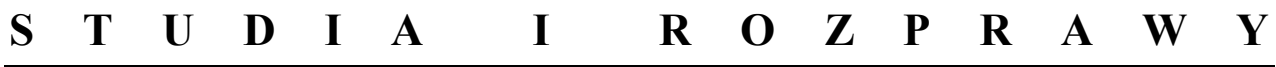

ROCZNIKI HUMANISTYCZNE

Tom LXIX, zeszyt $7 \quad 2021$

DOI: http://doi.org/10.18290/rh21697-1

AGNIESZKA LENART

\section{RUSYCYSTYKA W IZRAELU. \\ OD KULTUROWEJ SEPARACJI DO DEMARGINALIZACJI KULTURY ROSYJSKO-ŻYDOWSKIEJ}

Izrael w latach dwutysięcznych staje się jednym z ważniejszych ośrodków kultury rosyjskiej na świecie (Almog 232). Kolejne fale reprezentantów rosyjskojęzycznej alii, w dużej mierze przedstawicieli rosyjskiego świata nauki i kultury, wzmacniają poziom intelektualny izraelskiego państwa (Lenart 80). Po pierestrojce, kiedy do Izraela dociera około miliona rosyjskojęzycznych Żydów, w izraelskich uniwersytetach rośnie zapotrzebowanie na studia rusycystyczne. Rosyjskojęzyczne elity tworzą wówczas izraelską kadrę naukową i podejmują bądź kontynuują prowadzone wcześniej badania. Zajmuje ich głównie problematyka literaturoznawcza, skupiająca się na prozie emigracyjnej, piśmiennictwie prozaików pierwszej fali emigracji rosyjskiej, życiu i twórczości autorów, rozczarowanych - tak jak oni - sytuacją w Rosji, odtrąconych, wypchniętych za granicę. Rosyjskojęzyczne społeczeństwo w Izraelu żyje w kulturowej separacji (z czterech wyróżnionych przez Johna Berry'ego strategii adaptacyjnych - badacz pisze o adaptacji, integracji, marginalizacji i separacji (Grzymała-Kazłowska 179) - na określenie modelu funkcjonowania rosyjskojęzycznych imigrantów najbardziej trafna wydaje się ta ostatnia). Dominantą ich hybrydycznej, stale (re)definiowanej tożsamości jest język rosyjski (poprzez świadomy wybór lub „skazanie na język" (Adamczyk-Garbowska 177)), który dla co najmniej dwóch rosyjsko-izraelskich pokoleń wciąż daje możliwość bycia sobą - repatriantem z ZSRR/Rosji (por. Ricoeur 5).

Dr AgnieszKa Lenart - Uniwersytet Śląski w Katowicach, Wydział Humanistyczny, Instytut Literaturoznawstwa; e-mail: agnieszka.lenart@us.edu.pl; ORCID ID: 0000-0002-7467-2788. 
Celem podjętych badań jest próba omówienia kondycji rusycystyki w Izraelu. Kierunek dociekań wyznaczą okoliczności społeczno-polityczne, jakie wpłynęły na wzrost statusu języka rosyjskiego i dynamikę spadku jego atrakcyjności oraz perspektywy podtrzymania zainteresowania kulturą rosyjską. Przywołane zostaną nazwiska izraelskich rusycystów, pospołu z omówieniem ich dokonań na gruncie światowych badań slawistycznych, oraz czynniki, które wytyczyły preferencje badawcze izraelskich naukowcówslawistów. Interesować nas będzie głównie sytuacja izraelskiej rusycystyki. W kontekście izraelsko-słowiańskim to przede wszystkim język rosyjski i kultura rosyjska uzupełniają specyficzny izraelski tygiel. Należy wziąć pod uwagę, że masowa repatriacja rosyjskojęzycznych olim - a ta miała miejsce głównie w latach 70. i 90. XX wieku - to wyjazdy z (post)sowieckiej rzeczywistości. Trudno więc, biorąc pod uwagę okoliczności polityczno-społeczne, mówić o ukraińskiej, białoruskiej czy litewskiej identyfikacji. Żydzi z byłych republik radzieckich asymilują się w nowej ojczyźnie, tworząc „rosyjskojęzyczny Izrael”.

W nowo powstałym państwie Izraela polityka językowa jest jednym z ważniejszych narzędzi formowania wspólnej idei narodowej. W sprawnym budowaniu nowego państwowego bytu i wewnętrznej integracji jego obywateli ma pomagać hebraizacja (Famulska-Ciesielska 5). Z takim też założeniem w 1948 r. w Izraelu powołuje się Ulpan, instytuty, gdzie prowadzone są dla wielokulturowego społeczeństwa (dane statystyczne potwierdzają obecność w Izraelu reprezentantów trzydziestu dwóch języków) intensywne kursy języka hebrajskiego i zajęcia z kultury izraelskiej/żydowskiej. Jasno określone założenia syjonistyczne zakładają szybkie umacnianie się nowego państwa poprzez skuteczną absorbcję imigrantów i ich integrację w izraelskim społeczeństwie. Języki diaspory, tzw. gałuta, szybko tracą na znaczeniu, są marginalizowane, traktowane jako spowalniające proces integracji i akulturacji. Dla uporządkowania poliglotycznego tygla, aby odciąć repatriantów od przeszłości, co de facto wydaje się racjonalne z punktu widzenia tworzenia nowej państwowości, postępuje proces wdrażania języka hebrajskiego, który staje się symbolem narodowej identyfikacji Żydów-Izraelczyków (Przewrocka-Aderet 106).

W latach 70. XX wieku koncepcja „tygla narodów” staje się coraz mniej realna. Do Erec Israel docierają kolejne fale repatriantów, następuje „rozluźnienie presji hebraizacyjnej” (Famulska-Ciesielska 7), odradza się wielokulturowy Izrael. Rosyjskojęzyczni olim doskonale wykorzystują ten czas. Tworzą własną subkulturę, rosyjskojęzyczne panoptikum $-\mathrm{z}$ odrębnym 
systemem edukacji i ożywionym życiem kulturalnym. W szkołach pojawiają się zajęcia fakultatywne z języka rosyjskiego i literatury rosyjskiej, wprowadzane są programy nauczania języka rosyjskiego jako ojczystego, a znaczącą liczbę godzin, oprócz praktycznej nauki języka, poświęca się na zajęcia literackie. Oceny z tych przedmiotów znajdują się na świadectwie maturalnym.

Lata 90. XX wieku są nazywane „złotym wiekiem prasy rosyjskojęzycznej w Izraelu" (Almog 207), liczba zainteresowanych nauką rosyjskiego stale rośnie. W 1991 r. na zajęcia rusycystyczne uczęszcza około stu osób, sześć lat później - ponad dwa tysiące, na początku lat dwutysięcznych liczba licealistów podejmujących naukę rosyjskiego wynosi około dziesięciu tysięcy (Naydich). Pod koniec lat 90. rośnie liczba uczniów słabiej władających rosyjskim, ale kondycja rusycystyki wciąż jest bardzo dobra. Język rosyjski w programach nauczania zyskuje status języka obcego cieszącego się dużą popularnością. Oprócz zajęć z mówienia do programu włącza się ćwiczenia $\mathrm{z}$ gramatyki i pracy $\mathrm{z}$ tekstem.

Uzasadnienie takiego stanu rzeczy wydaje się proste. W latach 1970-1989 przybywa do Erec Israel prawie dwieście tysięcy Żydów z byłego ZSRR, w latach 1990-2003 - ponad dziewięćset tysięcy (Naydich). Społeczność rosyjskojęzycznych olim stanowi w tym czasie około dwudziestu procent społeczeństwa Izraela (Almog 207). Za sprawą nowo przybyłych imigrantów, po pierwsze, znacznie wzrasta odsetek osób z wyższym wykształceniem (około sześćdziesięciu procent repatriantów z ZSRR ma wyższe wykształcenie, podczas gdy wśród rodzimych Izraelczyków grupa osób wykształconych stanowi około dwudziestu procent (Naydich)), po drugie zaś rośnie liczba młodzieży studiującej i zainteresowanie kulturą wysoką (Almog 208), następuje odrodzenie „rosyjskiej duszy”. Rosyjskojęzyczni repatrianci niejako wymuszają na Ministerstwie Absorpcji wsparcie ich działalności kulturalnej (teatrów, bibliotek, księgarń, stowarzyszeń, czasopiśmiennictwa) (Lenart 247-250), rośnie status języka rosyjskiego (z hebrajskiego na rosyjski jest tłumaczona cała dokumentacja administracyjna, formularze, ankiety, broszury informacyjne). Takie działania są wygodne dla obu stron - niwelują społeczno-psychologiczne napięcie związane $z$ aklimatyzacją i ułatwiają pracę administracji państwowej (Semenchenko 14).

W latach dwutysięcznych obserwuje się stopniowy spadek zainteresowania językiem rosyjskim, który - obok angielskiego, francuskiego, arabskiego i hebrajskiego (to tymi językami coraz częściej posługuje się młodsze pokolenie repatriantów w krajów byłego ZSRR) - wydaje się coraz 
mniej atrakcyjny ${ }^{1}$ (215). Zdecydowany wpływ na taki kierunek zmian ma mniejsza liczba przybywających do Izraela rosyjskojęzycznych olim. W 2005 r. wybiera ten kraj już tylko dziesięć tysięcy repatriantów z Rosji. Nauczyciele rusycyści narzekają na trudności metodyczne, związane z nierównym poziomem językowym grup i konieczność ciągłego obniżania poziomu nauczania ze względu na coraz słabszą znajomość języka wśród uczącej się młodzieży. Dogłębnej rewizji wymagają także metody nauczania literatury. Teksty rosyjskojęzyczne sprawiają studentom coraz więcej problemów. Izraelski odbiorca gorzej zna realia rosyjskiego życia, z trudnością odczytuje kontekst historyczno-literacki, humor, ironię. Wielu uczniów i studentów posługuje się językiem nieliterackim, mową potoczną, głównie językiem mówionym, „rodzinnym”. Język literacki, czysty, pisany dla wielu staje się już tylko symbolem przeszłości i utrwalonych wartości. Stopniowe odchodzenie od języka dawnej ojczyzny jest rzeczywistym znakiem tworzenia się nowej (rosyjsko-)izraelskiej tożsamości, zachodzących w społeczeństwie przemian kulturowo-społecznych, u młodych wzmacnianych ponadto pogonią za duchem postępu i nowoczesności.

Kwestia zachowania języka lub jego utraty zależy od wielu czynników motywów demograficznych, socjalnych, kulturowych. O wyborze orientacji językowej często decyduje mikrośrodowisko, stanowiące przestrzeń życiową repatrianta (w miejscowościach Riszon le-Cijjon, Bat Jam, Aszkelon, Górny Nazaret rosyjskojęzyczna ludność stanowi znaczący odsetek mieszkańców, największym skupiskiem rosyjskich Żydów jest Hajfa (235)). Do dziś młode pokolenie rosyjskojęzycznych repatriantów funkcjonuje raczej w dwóch kręgach językowych. Pierwszy można nazwać orientacją rosyjską, gdzie integracja następuje wolniej i w większym stopniu zachowana jest rosyjska tożsamość - sprzyja temu, rzecz jasna, wielkość społeczności rosyjskojęzycznej $\mathrm{w}$ danym miejscu, mieście czy regionie, i drugi, zorientowany na język hebrajski, gdzie szybciej postępuje asymilacja/absorbcja. Często, jak twierdzi Michaił Wajskopf, dzieci repatriantów z krajów byłego ZSRR tworzą zwarte środowisko, funkcjonują $\mathrm{w}$ rosyjskojęzycznej subkulturze, w warunkach

\footnotetext{
${ }^{1}$ Wydarzeniami w pewnym sensie przełomowymi, które zjednoczyły Izraelczyków i zasymilowały społeczeństwo, a jednocześnie nieco zdestabilizowały rosyjskojęzyczną aliję (wielu przecież wybrało Izrael, aby zapewnić swoim dzieciom bezpieczną przyszłość), żyjącą w pewnym odseparowaniu, będącą grupą marginalizowaną, są powstania, bunty Palestyńczyków nazywane Intifadą Al-Aksa. Zamachy samobójcze, w tym tragiczne wydarzenie z dyskoteki w Tel-Awiwie, gdzie ginie 17 osób, a 120 zostaje rannych, określane mianem ,zamachu terrorystycznego na Rosjan”, wzmacniają asymilację społeczną Izraelczyków i izraelski model kulturowy staje się dominujący również dla wielu rosyjskojęzycznych olim.
} 
kulturowego pluralizmu. Mimo wszystko językiem dominującym coraz częściej staje się u nich hebrajski (Vayskopf; Almog 231). Grupą utrzymującą najbardziej żywy kontakt z językiem rosyjskim i kulturą rosyjską są rosyjscy Żydzi negatywnie oceniający funkcjonowanie Państwa Izrael i ze słabą motywacją do nauki hebrajskiego (Olshtain i Kotik 212-215). Chroniona przez nich kultura rosyjska jest symbolem domu, utraconej ojczyzny, również jako przeciwwaga do wspomnień o ZSRR/Rosji - kraju politycznego reżimu (Naydich).

\section{IZRAELSKA SLAWISTYKA I BADANIA RUSYCYSTYCZNE - STAN I PERSPEKTYWY ROZWOJU}

O kondycji slawistyki w czasie dla tej dyscypliny dosyć dobrym (rok 2007) mówi Wolf Moskowicz na konferencji w Weronie (Aloe). Spotkanie odbywa się w ramach prac Międzynarodowej Komisji Historii Slawistyki (powołana w Belgradzie w 1955 r. jako jednostka wspierająca działania Międzynarodowego Komitetu Slawistów). Moskowicz podkreśla znaczący wkład izraelskich slawistów w międzynarodowe badania słowianoznawcze i rozwój dyscypliny, z mniejszym optymizmem jednak ocenia przyszłość izraelskiej slawistyki (Aloe).

Studia wyższe w zakresie języków słowiańskich, literatury i kultury rosyjskiej oraz kinematografii prowadzone są w Uniwersytecie Hebrajskim w Jerozolimie. Tamtejsza Katedra Slawistyki wyłania się z Katedry Komparatystyki przy zaangażowaniu Lei Goldberg i Wiery Dołżańskiej. Uniwersytecki ośrodek badań slawistycznych stopniowo staje się najbardziej prężnie działającym ośrodkiem naukowo-badawczym w Izraelu w zakresie języka rosyjskiego, języków słowiańskich, literatury i kultury rosyjskiej. W latach 60. XX wieku ruszają badania sowietologiczne.

W kolejnych latach, kiedy do Izraela przybywa duża grupa repatriantów ze Związku Radzieckiego, a wraz z nią specjaliści-slawiści - lingwista Wiktor Lewin, literaturoznawca i semiotyk Dmitrij Segal, historycy Teodor Friedgut, Jonatan Frenkel, badacz literatury Borysa Pasternaka Lazar Fleishman, lingwista i kulturoznawca Wolf Moskowicz - następuje szybki rozwój badań slawistycznych, uruchamiane są studia nad rosyjską, sowiecką i wschodnioeuropejską historią, prowadzone są prace w zakresie literatury rosyjskiej i literatur słowiańskich oraz lingwistyki. Kierunek slawistycznych działań naukowych kadry Uniwersytetu w Jerozolimie wyznaczają tradycje tartusko- 
moskiewskiej szkoły semiotycznej i rosyjskiego formalizmu, kreślą osiągnięcia Moskiewskiego Koła Lingwistycznego oraz petersburskiego Instytutu Literatury Rosyjskiej („Пушкинский Дом [Pushkinskiy Dom]”). W latach 1970-1990 w ramach prac naukowo-badawczych katedra wydaje literaturoznawcze czasopismo naukowe Slavica Hierosolimytana (w redakcji czasopisma pracują: Lazar Fleishman, Omry Ronen, Dmitrij Segal, Wolf Moskowicz). W periodyku publikują swoje teksty Gleb Struwe, Roman Jakobson, Benjamin Hrushovski, Isaiah Berlin, Władimir Toporow, Wiaczesław Iwanow. Kolejne numery zawierają, oprócz opracowań klasyki literatury rosyjskiej (Aleksandr Puszkin, Fiodor Dostojewski, Nikołaj Gogol), prace poświęcone pisarstwu rosyjskiego modernizmu - twórczości Dymitra Mereżkowskiego, Osipa Mandelsztama, Walerija Briusowa, Aleksandra Błoka, Niny Bierbierowej, Borysa Pasternaka, Władmira Majakowskiego, Wasilija Rozanowa. Misją czasopisma jest tworzenie przestrzeni, w której literatura jest traktowana jako "zaszyfrowany zapis”, „tropologiczna reprezentacja” (Nycz, 12) i jest odzwierciedleniem rzeczywistości (Segal 22). Największy rozwój katedry przypada na przełom lat 80. i 90. XX wieku. W Uniwersytecie Hebrajskim znajdują zatrudnienie historycy literatury: Jelena Tołstoj (Chuprynin 267-268), wnuczka Aleksieja Tołstoja, „obrończyni kultury rosyjskiej”, i jej mąż Michaił Wajskopf (Vayskopf 236-237). Naukowcy wspominają początki swojej kariery naukowo-badawczej jako najlepszy czas dla izraelskiej rusycystyki. Kalendarz ważnych wydarzeń wyznaczała wówczas, jak twierdzą, kolejna rocznica śmierci Aleksandra Puszkina. Wtedy też Katedra Slawistyki Uniwersytetu Jerozolimskiego w szybkim tempie się rozwija (Silayev). Oprócz naturalnych socjo-kulturowych przyczyn stopniowego zamierania katedry w latach dwutysięcznych Wajskopf wymienia, po pierwsze, wprowadzenie systemu bolońskiego, co wpłynęło na osłabienie kondycji całej humanistyki; po drugie, wszechobecną modę na konsolidację kierunków (z połączenia Katedry Slawistyki z Katedrą Germanistyki powstaje Katedra Badań Niemieckich, Rosyjskich i Wschodniosłowiańskich); po trzecie, podaje jeszcze jeden kuriozalny, ale często prawdziwy powód, dla którego młodzież wybiera studia filologiczne. Są to, jak twierdzi, problemy z matematyką (Silayev). Istotny wkład w rozwój jerozolimskiej slawistyki ma Roman Timenczyk, słowianoznawca, literaturoznawca, uczeń Jurija Łotmana. Badania naukowe Timenczyka dotyczą literatury rosyjskiej okresu modernizmu i twórczości przedstawicieli okresu Srebrnego Wieku, Anny Achmatowej i środowiska literackiego skupionego wokół petersburskiej kawiarni „Brodiaczaja sobaka” i krymskiego domu Aleksandra Smirnowa 
w Ałuszcie, gdzie odbywały się spotkania literackie z udziałem O. Mandelsztama, M. Wołoszyna, N. Gumilowa ${ }^{2}$. Pod redakcją Timenczyka wychodzą zbiory Vladimira Nabokova, Iwana Bunina, Michaiła Kuźmina, Lwa Gumilowa i Władimira Piasta. W 2006 r. badacz wraz z Władimirem Chazanem jako współautorem wydaje monografię poświęconą poezji pierwszej i drugiej fali emigracji rosyjskiej Петербург в поэзии русской эмиграчии [Peterburg $v$ poezii russkoy emigratsii]. Timenczyk ma udział w opracowaniu sześciotomowego słownika biograficznego Русские писатели 1800-1917 [Russkiye pisateli 1800-1917]; ostatni tom ukazał się w lutym 2020 r. (Chuprynin 267).

Naukowca interesują rosyjsko-żydowskie związki literackie, stąd jego dociekania o charakterze heurystycznym. To właśnie poszukiwania nowych literackich kontekstów i historyczno-literackich faktów, docieranie do nieodkrytych dotąd wątków biograficznych, głównie twórców emigracyjnych okresu Srebrnego Wieku zajmowało i wciąż zajmuje badacza. Uczony jest zwolennikiem komentowania, objaśniania, literackiego namysłu nad literaturą. Poznawcza metoda pracy $\mathrm{z}$ tekstem literackim, jak twierdzi, nie jest „objawem dyscyplinarnego wyjałowienia” (Dąbrowski 64-71), ale potrzeby ożywionej dyskusji: „С текстом надо работать, и только потом, по выходным, предаваться размышлениям об эмоциях, своих и автора, воплощенных и вызванных этим текстом, о всяких вечных ценностях, обнаруженных в нем" - przekonuje Timenczyk (Timenchik 31).

Według koncepcji Timenczyka zadaniem literaturoznawcy, historyka literatury jest podejmowanie próby odtworzenia utraconego sensu tekstu (sens mógł się zagubić gdzieś po drodze, szczególnie, jeśli mamy do czynienia z tekstem dawnym), nawet jeśli ta praca nie jest wolna od błędnych interpretacji. Tekst i obrazy same powinny nieść swoją historię. Wówczas mają największą siłę oddziaływania na odbiorcę. Dlatego tak istotne jest, według teorii Timenczyka, poszukiwanie kodu, jakim posługiwał się współczesny autorowi czytelnik. Pracę z tekstem, jak twierdzi badacz, ułatwiają przypisy i komentarze, które, chociaż czasem przeszkadzają w odbiorze tekstu, bo odciągają uwagę od tekstu głównego, są „estetycznym złem”, są także wskazówką poprawnego odczytania tekstu historycznego. Bez znajomości tradycji literackiej szczególnie trudno jest zrozumieć rosyjskojęzyczny tekst pisany we współczesnym Izraelu (32).

\footnotetext{
${ }^{2}$ Obszerna informacja o dorobku Timenczyka jest dostępna na stronie Uniwersytetu w Toronto: University of Toronto, Academic Electronic Journal in Slavic Studies, Toronto Slavic Quarterly, „Роман Давидович Тименчик. Библиография [Roman Davidovich Timenchik: Bibliografiya]”, http://sites.utoronto.ca/tsq/14/timenchikbiblio14.shtml, dostęp 26.03.2020.
} 
Poezja rosyjska XX wieku i literatura emigracyjna, pisarstwo rosyjskiej zagranicy, szczególnie tzw. pierwszej fali rosyjskiego Paryża (twórczość Borysa Popławskiego, Władimira Warszawskiego, Gennadija Chomiakowa) zajmuje Władimira Chazana. Profesor angażuje się w projekt wydawniczy Литературные журналы русского Парижа (1920-1940) [Literaturnyye zhurnaly russkogo Parizha (1920-1940)], wspiera działalność naukową Domu Rosyjskiej Zagranicy. Obecnie Chazan redaguje nową, wielotomową serię Eretz-Israel and the Russian Émigrés in Europe: Contacts, Connections, Communications, Interactions (1919-1939).

Badania slawistyczne w Uniwersytecie Hebrajskim prowadzą także: urodzony w Krakowie Mojsze Taube, językoznawca, specjalizujący się w rosyjsko-hebrajskim przekładzie, Aleksandr Kulik, badacz średniowiecznej i współczesnej judeo-slawistyki, Walentyna Brio, prowadząca badania nad poezją i poetyką miasta oraz Nina Segal-Rudnik, w której kręgu zainteresowań pozostaje literatura Srebrnego Wieku, twórczość Wiaczesława Iwanowa, Andrieja Biełego, Wiktora Szkłowskiego oraz związki twórcze tych autorów z literaturą Złotego Wieku i tradycją literacką Dostojewskiego, Gogola i Tołstoja.

Od 1993 r. w wydawnictwie uniwersyteckim, pod redakcją Wolfa Moskowicza, Szmuela Szwarzbanda i Anatolija Aleksiejewa, wydawana jest seria naukowa Jews and Slavs [Żydzi i Słowianie], z założenia i w praktyce będąca forum wymiany myśli naukowej slawistów z Izraela i z zagranicy. Do kwietnia 2020 r. wyszło 25 tomów. Kolejne części są wyrazem naukowych poszukiwań żydowsko-slawistycznych związków kulturowych, obecności wątków żydowskich w piśmiennictwie narodów słowiańskich i w badaniach slawistycznych. Sam Moskowicz pełni funkcję przewodniczącego Izraelskiego Towarzystwa Ukrainistów (od 1993 r.) i Izraelskiego Towarzystwa Slawistów (lata 1990-2002). Równolegle prowadzi badania nad językiem i kulturą jidysz oraz reprezentuje izraelską ukrainistykę, kierunek w Izraelu niszowy.

Katedra Slawistyki Uniwersytetu Hebrajskiego jest organizatorem cyklicznych kongresów bachtinowskich, konferencji puszkinowskich, spotkań poświęconych życiu i twórczości Borysa Pasternaka oraz cyklu konferencji o kondycji literatury rosyjskiej po upadku komunizmu.

Slawistyka prężnie działa w Uniwersytecie w Hajfie. Hajfa, największe miasto północnej części Izraela, jest ważnym ośrodkiem naukowym i kulturalnym. Na szczycie Góry Karmel ulokowany jest kampus tamtejszego uniwersytetu, w pobliżu również Instytut Technologii - Technion. Miasto jest jednym z większych skupisk rosyjskich Żydów w Izraelu (Almog 207). 
Z tego też powodu, jak twierdzi Natalia Roitberg, hajfska slawistyka nie ma problemu z naborem studentów. Studia slawistyczne, głównie rusycystyczne, podejmują kandydaci z rodzin, gdzie przynajmniej jedno z rodziców posługuje się językiem rosyjskim ${ }^{3}$. W zajęciach z języka rosyjskiego i literatury rosyjskiej coraz częściej biorą udział studenci z Chin, Rumunii, Słowacji i Stanów Zjednoczonych. Dla nich studia odbywają się w języku angielskim bądź hebrajskim. Studenci z zaawansowaną znajomością języka rosyjskiego, słuchacze dwujęzyczni lub z kompetencjami natywnymi realizują program nauki języka i literatury w języku rosyjskim. Slawistyczne badania w Hajfskim Uniwersytecie prowadzą literaturoznawcy Denis Sobolev, Larysa Fiałkowa i Władimir Papiernyj oraz językoznawcy Natalia Roitberg i Natalia Gordinskaja.

Od 1971 r. na Wydziale Humanistycznym Uniwersytetu w Tel-Awiwie działa Instytut Rosji i Europy Wschodniej. Wkład w rozwój Instytutu ma Michael Confino, naukowiec bułgarskiego pochodzenia, specjalizujący się w historii Rosji, absolwent Sorbony, później pracownik naukowy Uniwersytetu Harvarda. W centrum prowadzone są badania sowietologiczne, postsowietologiczne i wschodnioznawcze. W największej izraelskiej uczelni, w Uniwersytecie Telawiwskim, badania wschodniosłowiańskie są uprawiane rzadko.

$\mathrm{Na}$ tle izraelskich badań wschodniosłowiańskich wyraźnie wyróżnia się ponadto działalność dwóch slawistów - badaczy międzynarodowych. Pierwszy z nich to Zachar Dawidow, urodzony w Kijowie, od 1991 r. związany z Uniwersytetem Hebrajskim w Jerozolimie, później pracownik naukowy Uniwersytetu w Toronto. Dawidow, znawca twórczości Maksymiliana Wołoszyna, pracuje w kanadyjskim uniwersytecie w Katedrze Literatur i Języków Słowiańskich, a od 2002 r. redaguje czasopismo Toronto Slavic Quarterly. Druga ważna postać to nieżyjący już Władimir Gitin, literaturoznawca, profesor Instytutu Slawistyki Uniwersytetu Harvarda ${ }^{4}$. Dorobek naukowca stanowią niepublikowane wcześniej utwory Innokientija Annienskiego, a wśród nich poemat Магдалина [Magdalina; Magdalena] (1997), История античной драмы [Istoriya antichnoy dramy; Historia dramatu antycznego] (2003), Teaтр Еврипида [Teatr Yevripida; Teatr Eurypidesa] (2007), Речь Иннокентия Анненского о Кирилле и Мефодии [Rech' Innokentiya Annenskogo o Kirille i Mefodii; Stowo Innokientija Annienskiego o Cyrylu i Metodym] (2009).

\footnotetext{
${ }^{3}$ Na podstawie korespondencji autorki artykułu z Natalią Roitberg, 15.04.2020.

${ }^{4}$ Harvard University, Department of Slavic Languages \& Literatures, „In Memoriam: Vladimir Gitin (January 23, 1942 - June 8, 2019)", slavic.fas.harvard.edu/news/memoriam-vladimirgitin-january-23-1942-june-8-2019, dostęp 26.03.2020.
} 
Izraelska rusycystyka, jej rozwój i stopniowe jej wygaszanie wpisuje się w społeczno-kulturowy układ wielokulturowego kraju, a także w globalne, międzynarodowe trendy naukowe. Nie ma złudzeń, że izraelska rusycystyka, w pierwotnym jej wydaniu, powróci. Kadry naukowe, specjaliści zakorzenieni w kulturze rosyjskiej kończą bądź zakończyli karierę zawodową. O ile starsze pokolenie olim, po przyjeździe do Izraela, mogło funkcjonować w rosyjskojęzycznym ,społeczeństwie w miniaturze”, w emigracyjnej heterotopii (za: Foucault 118-119), gdzie ważny był kapitał wiążący, to jest wspomnienie o przeszłości, młodsze pokolenia są już tam zakotwiczone (Pucek 31) i odcięte od centrum kulturowego przodków. Coraz częściej zresztą, jak twierdzi Zygmunt Bauman, przywiązanie do miejsc traci na znaczeniu (7). W cenie jest możliwość swobodnego dryfowania w zglobalizowanym świecie (29) i mobilność, która staje się jedną z nadrzędnych wartości młodych ludzi. Kultura izraelska, podobnie jak cała współczesna rzeczywistość, przypomina „chaotyczny konglomerat, „układ postpluralistyczny”, „strefę kontaktu”, „kulturowy kalejdoskop”, „kolaż” (Pucek 36-37; Clifford 203-272), sprzyja dehierarchizacji i tożsamościowemu rozmyciu (Raźny 9). Wydaje się, że w obecnych czasach traci na znaczeniu tak ważne w kulturze żydowskiej zamiłowanie do wielojęzyczności, słabnie szacunek do słowa i wysoka ranga wykształcenia humanistycznego (Wołk 11).

$\mathrm{Na}$ specyfikę badań rusycystycznych prowadzonych w Izraelu wpływa zainteresowanie tamtejszych badaczy literaturą rosyjskiej zagranicy, twórczością emigracji rosyjskiej, szczególnie pierwszej fali. Duży obszar badawczy zakreślają prace translatologiczne, tłumaczenia na hebrajski, zarówno tekstów klasycznej literatury rosyjskiej, jak i literatury najnowszej, pisanej po rosyjsku w Izraelu. Coraz częściej izraelscy rusycyści podejmują namysł nad literaturą rosyjskojęzyczną, wpisując ją w żydowskie i izraelskie konteksty.

Roman Katsman, literaturoznawca z Uniwerystetu Bar-Ilan w Tel-Awiwie, pisze o postępującym procesie demarginalizacji kultury rosyjskojęzycznej, szczególnie literatury rosyjsko-izraelskiej i rosyjsko-żydowskiej (Katsman; Michalska-Suchanek 182). Badacz zwraca uwagę na fakt stopniowego odłączania się literatury rosyjskojęzycznej pisanej w Izraelu od literatury rosyjskiej, a jednocześnie stanowiącej także odrębną gałąź względem literatury natywnej, tworzonej w języku hebrajskim. Twierdzi, że dominujące dotychczas kody kulturowe obu kultur zostają wyparte przez nową literaturę (Famulska-Ciesielska 5), gdzie mniej ważne stają się wartości kulturowe, narodowe, etniczne, a zyskują na znaczeniu doświadczenia $\mathrm{z}$ egzystencji w wielokulturowym, transkulturowym świecie. Język rosyjski, według Katsmana, 
nie jest tu synonimem nostalgii, więzi z przeszłością i dawną ojczyzną. Język jest, jak twierdzi badacz, jedynie narzędziem komunikacji (Katsman 183-184). Już niebawem w telawiwskiej uczelni rusza projekt, którego założeniem jest podjęcie badań nad historią literatury rosyjskojęzycznej w Izraelu i spojrzenie na tę twórczość jako na odrębny fenomen kulturowy, wymagający również wypracowania odpowiednich metod badawczych.

Kondycja izraelskiej rusycystyki w najlepszych dla niej latach, w ostatniej dekadzie XX i na początku XXI wieku, jest odzwierciedleniem potrzeb kulturowej separacji i typowego dla kultury rosyjskiej poczucia wspólnotowości (por. Raźny 9), duchowego przywiązania do rosyjskości i języka rosyjskiego. Za demarginalizacją kultury rosyjsko-żydowskiej, rosyjsko-izraelskiej przemawia wciąż żywa potrzeba kulturowej autonomii i niezgoda na przypisanie do kultury peryferyjnej.

\section{BIBLIOGRAFIA}

Adamczyk-Garbowska, Monika. Odcienie tożsamości. Literatura żydowska jako zjawisko wielojęzyczne. Wydawnictwo Uniwersytetu Marii Curie-Skłodowskiej, 2004.

Almog, Oz. Wielokulturowy Izrael. Tłum. Agnieszka Olek, Aleksandra Rawska, Wojciech Tworek. Wydawnictwo Wyższej Szkoły Pedagogicznej TWP, 2011.

Aloe, Stefano. „Razvitiye slavyanovedeniya v yevropeyskikh imperiyakh. Materialy Mezhdunarodnoy konferentsii”. Slavyanovedeniye, $\mathrm{nr}$ 4, 2008, ss. 121-124 [Алоэ, Стефано. «Развитие славяноведения в европейских империях. Материалы Международной конференции Комиссии по Истории Славистики при МКС»., Славяноведение, № 4, 2008, cc. 121-124].

Bauman, Zygmunt. Globalizacja. I co z tego dla ludzi wynika. Tłum. Ewa Klekot. Państwowy Instytut Wydawniczy, 2000.

Chuprynin, Sergey. Russkaya literatura segodnya: Zarubezh'ye. Vremya, 2008. [Чупрынин Сергей. Русская литература сегодня: Зарубежье. Время, 2008].

Clifford, James. Kłopoty z kultura: Dwudziestowieczna etnografia, literatura i sztuka. Tłum. Ewa Dżurak. Wydawnictwo KR, 2000.

Dąbrowski, Stanisław. „Pogardzana służba. O komentowaniu prac literaturoznawczych”, Teksty Drugie, nr 6, 1996, ss. 64-71.

Famulska-Ciesielska, Karolina, i Sławomir Jacek Żurek. Literatura Polska w Izraelu. Leksykon. Austeria, 2012.

Foucault, Michel. „Inne przestrzenie”. Tłum. Agnieszka Rejniak. Teksty Drugie, nr 6, 2005, ss. 117-125.

Grzymała-Kazłowska, Aleksandra, i Piekut Aneta. „Integracja migrantów w społeczeństwie przyjmującym”. 25 wykładów o migracjach, red. Magdalena Lesińska i Marek Okólski, Wydawnictwo Naukowe Scholar, 2018, ss. 178-196. 
Katsman, Roman, „Demarginalization of Contemporary Russophone Literature in Israel”, www.academia.edu/35544512/Demarginalization_of_Contemporary_Russophone_Literat ure_in_Israel. Dostęp 26.03.2020.

Lenart, Agnieszka. „Kultura literacka rosyjskojęzycznego Izraela. Spory wokół „narodowości” literatury". Archiwum Emigracji, z. (1-2) 20-21, 2014, ss. 80-90.

Lenart, Agnieszka. „W poszukiwaniu tożsamości. „Polskie” i „,rosyjskie” życie literackie w Izraelu". Literatura polsko-żydowska. Studia i szkice, red. Eugenia Prokop-Janiec i Sławomir Jacek Żurek, Księgarnia Akademicka, 2011, ss. 245-252.

Michalska-Suchanek, Mirosława. „Najnowsza literatura rosyjsko-izraelska. Zarys zagadnienia”. Przeglad Rusycystyczny, nr 1(169), 2020, ss. 180-197.

Naydich, Larisa. „Novaya aliya sokhranyayet russkiy”. Otechestvennyye zapiski, nr 2(23), 2005, www.strana-oz.ru/2005/2/novaya-aliya-sohranyaet-russkiy. Dostęp 10.05.2020 [Найдич, Лариса. «Новая алия сохраняет русский». Отечественные записки, № 2(23), 2005, www.strana-oz.ru/2005/2/novaya-aliya-sohranyaet-russkiy].

Nycz, Ryszard. Literatura jako trop rzeczywistości. Poetyka epifanii w nowoczesnej literaturze polskie. Universitas, 2001.

Olshtain, Elite, i Bella Kotik. „The Development of Bilingualism in an Immigrant Community Language". Identity and Immigration, red. Elite Olshtain, Gabriel Horenczyk. Magnes, 2000, ss. 212-215.

Przewrocka-Aderet, Karolina. Polanim. Z Polski do Izraela. Wydawnictwo Czarne, 2019.

Pucek, Zbigniew. „Tożsamość w przestrzeni wielokulturowej”. Państwo i Spoleczeństwo nr 3, 2004, ss. 25-42.

Raźny, Anna. „Słowo wstępne”. Tożsamość, indywidualizm, wspólnotowość w kulturze rosyjskiej, red. Anna Raźny. Wydawnictwo Uniwersytetu Jagiellońskiego, 2014, ss. 7-9.

Ricoeur, Paul. O sobie samym jako innym. Tłum. Bogdan Chełstowski. Wydawnictwo Naukowe PWN, 2003.

Segal, Dimitriy. „Literatura kak vtorichnaya modeliruyushcha sistema”. Slavica Hierosolimytana, $\mathrm{nr}$ 4, 1979, ss. 1-35 [Сегал, Димитрий. «Литература как вторичная моделирующа система». Slavica Hierosolimytana, № 4, 1979, nr 4, cc. 1-35].

Semenchenko, Nina. „Status russkogo yazyka v Izraile”. Tezisy i doklady 7-oy nauchnoy mezhinstitutskoy konferentsii Rossiyskaya diaspora v stranakh Vostoka, red. Dar'ya Panarina, Institut vostokovedeniya RAN, 2016 [Семенченко, Нина, «Статус русского языка в Израиле». Тезисы и доклады 7-ой научной межинститутской конференции Российская диаспора в странах Востока, ред. Дарья Панарина, Институт востоковедения РАН, 2016].

Silayev, Aleksandr. „Mikhail Vayskopf: Romantik idet po zhizni kak lunatik po karnizu”. Vecherniy Krasnoyarsk, nr 39 (280), newslab.ru/article/33912. Dostęp 23.05.2020. [Силаев, Александр. «Михаил Вайскопф: Романтик идет по жизни как лунатик по карнизу». Вечерний Красноярск, № 39 (280)].

Timenchik, Roman. Chto vdrug. Stat'i o russkoy literature proshlogo veka. Mosty kul'tury, 2008 [Тименчик, Роман. Что вдруг. Статьи о русской литературе прошлого века. Мосты культуры, 2008].

Vayskopf, Mikhail. „Stena ili simbioz, muzey ili zhivoy bum?”. Booknik, 2006, booknik.ru/ today/all/stena-ili-simbioz-muzeyi-ili-jivoyi-bum/. Dostęp 10.05.2020 [Вайскопф, Миха- 
ил. «Стена или симбиоз, музей или живой бум?», Booknik, 2006, booknik.ru/today/ all/stena-ili-simbioz-muzeyi-ili-jivoyi-bum/].

Wołk, Marcin. „O literaturze żydowskiej w językach nieżydowskich - wprowadzenie”. Archiwum Emigracji, z. (1-2) 20-21, 2014, ss. 9-22.

Zil'berg, Narspi. „Russkiye yevrei v Iyerusalime: kul'turnyye kody i manifestatsiya etnichnosti”, Vremya iskat', nr 6, 2002, ss. 141-162 [Зильберг, Нарспи. «Русские евреи в Иерусалиме: культурные коды и манифестация этничности». Время искать, № 6, 2002, cc. 141-162].

\section{RUSYCYSTYKA W IZRAELU. \\ OD KULTUROWEJ SEPARACJI DO DEMARGINALIZACJI KULTURY ROSYJSKO-ŻYDOWSKIEJ}

\section{Streszczenie}

Celem badań jest omówienie kondycji izraelskiej rusycystyki. W tekście wskazuje się uwarunkowania społeczno-polityczne, które wpłynęły na wzrost rangi języka rosyjskiego, omawia się dynamikę spadku jego atrakcyjności, a także perspektywy zainteresowania kulturą rosyjską w Izraelu. Autorka artykułu wymienia nazwiska izraelskich rusycystów i slawistów, omawia ich preferencje badawcze i osiągnięcia w zakresie światowych badań slawistycznych. Badania izraelskich rusycystów dotyczą przede wszystkim literatury pierwszej fali emigracji rosyjskiej. W ostatnim czasie coraz częściej podejmowane są prace nad literaturą rosyjską w kontekście żydowskim i izraelskim. Z przeprowadzonej analizy wynika, że rusycystyka w Izraelu najbardziej intensywnie rozwijała się w latach 90 . W XXI wieku zainteresowanie rusycystyką w Izraelu spada ze względu na słabszą znajomość języka i kultury rosyjskiej wśród młodszego pokolenia repatriantów. Wpływ na ten stan rzeczy mają także tendencje światowe i procesy globalizacyjne.

Slowa kluczowe: rusycystyka w Izraelu; rosyjski w Izraelu; demarginalizacja kultury rosyjskożydowskiej; kulturowa separacja.

\section{RUSSIAN STUDIES IN ISRAEL: FROM CULTURAL SEPARATION TO THE DEMARGINALISATION OF RUSSIAN-JEWISH CULTURE}

Su m m a ry

The objective of this research is to discuss the state of Russian studies in Israel. The area the study focuses on are the socio-political circumstances which have influenced the growth of the status of the Russian language, the dynamics of the decline of its attractiveness, and also the perspectives of maintaining interest in Slavic culture. This article gives the names of various Israeli Slavists and discusses their achievements in the field of Slavic research, as well as those factors which have narrowed their academic preferences. So far, the concern of Israeli Rusicists has been focused on the literature of the First Wave of Russian emigration. Recently, however, more and more frequently it refers to Russian literature in Jewish and Israeli contexts. The analysis conducted indicates that Russian studies flourished the most in the 1990s. In the $21^{\text {st }}$ century, interest in Russian studies in Israel 
is decreasing due to a poorer knowledge of Russian language and culture among the younger generation of repatriated people, worldwide trends and the processes of globalisation.

Keywords: Russian studies in Israel; Russian in Israel; demarginalisation of Russian-Jewish culture; cultural separation. 